\title{
A FILOSOFIA COMO PROPOSTA DE REFLEXÃO NA AÇÃO DO COORDENADOR PEDAGÓGICO
}

\author{
Paula de Morais PEREIRA* \\ Walteno Martins Parreira JÚNIOR**
}

Resumo: Neste trabalho encontra-se uma proposta para uso da Filosofia como diretriz no trabalho do supervisor pedagógico. Essa proposta se baseia em artigos / livros lidos sobre a importância da Filosofia como reflexão contínua e diária de pensamentos e ações. É sabido que a Filosofia é de suma importância para um bom processo de ensino-aprendizagem, fundamental na vida prática e também como diretriz para o pedagogo que orienta docentes. $\mathrm{O}$ trabalho do coordenador pedagógico é diário e rotineiro. Muitas vezes impregnado de tarefas, metas e padrões que engessam, de certa maneira, a forma como será conduzido o trabalho de orientação dos professores. Os coordenadores diante dos manuais que os orientam em seu trabalho promovem mais um repasse de modelos de ações e condutas do que uma construção coletiva e participativa com os professores na práxis pedagógica. O professor, conforme orientação do coordenador assume uma atitude passiva no momento de construção das ações pedagógicas que norteiam sua prática pedagógica. Ou seja, ele não participa e nem reflete na ação de produção de conhecimento. $\mathrm{O}$ presente estudo pretende verificar essa situação de passividade do professor e coordenador. Como essa situação limita as possibilidades de reflexão e construção coletiva da ação pedagógica e a possibilidade de uma orientação reflexiva quando no uso da Filosofia ou suas imprescindíveis características.

\footnotetext{
* Especialista em Coordenação Pedagógica pela Universidade Federal de Uberlândia. E-mail: aluapmorais@yahoo.com.br.

${ }^{* *}$ Mestre em Educação pela Universidade Federal de Uberlândia. waltenomartins@yahoo.com.
} 
Palavras-chave: Filosofia, Supervisor, Orientação, Coordenação pedagógica.

\begin{abstract}
In this work we present a proposal for the use of Philosophy as guideline in the work of the pedagogical supervisor. This proposal is based on articles / books read about the importance of Philosophy as a continuous and daily reflection of thoughts and actions. It is wellknown that Philosophy is of paramount importance for a good teachinglearning process, fundamental in practical life and also as a guideline for the teacher who guides teachers. The work of the pedagogical coordinator is daily and routine. Often impregnated with tasks, goals and standards that, in a certain way, shape the way in which teacher orientation work will be conducted. The coordinators before the manuals that guide them in their work promote a more pass-through of models of actions and behaviors than a collective and participatory construction with the teachers in the pedagogical praxis. The teacher, according to the orientation of the coordinator takes a passive attitude at the moment of construction of the pedagogical actions that guide his pedagogical practice. That is, it does not participate and does not reflect in the action of knowledge production. The present study intends to verify this situation of passivity of the teacher and coordinator. How this situation limits the possibilities of reflection and collective construction of the pedagogical action and the possibility of a reflexive orientation when in the use of the Philosophy or its essential characteristics.
\end{abstract}

Keywords: Philosophy, Supervisor, Guidance, Pedagogical coordination. 


\section{INTRODUÇÃO}

A Filosofia é uma das mais antigas propostas de conhecimento do processo educacional. Desde seu surgimento na polis da Grécia antiga, vem contribuindo significativamente para produção de um conhecimento crítico e autônomo. Essa criticidade, rigor, autonomia podem ser essenciais para o bom trabalho do supervisor pedagógico, promovendo orientação crítica, fundamentada e incentivando o professor a elaborar um trabalho docente com essas características fundamentais.

Nas relações entre filosofia e educação só existem realmente duas opções: ou se pensa e se reflete sobre o que se faz e assim se realiza uma ação educativa consciente; ou não se reflete criticamente e opaca o existente na cultura da vida do dia-a-dia - e assim se realiza uma ação educativa com baixo nível de consciência. [...] Filosofia e educação, pois, estão vinculadas no tempo e no espaço. Não há como fugir dessa 'fatalidade' da nossa existência. Assim sendo, parece-nos ser mais válido e mais rico, para nós e para a vida humana, fazer esta junção de uma maneira consciente, como bem cabe a qualquer ser humano [...] (LUCKESI, 1995, p.32-33).

É o que também é discutido por Saviani (1973), a Filosofia apresenta várias características fundamentais ao educador, mas uma em 
especial, a reflexão, é essencial aos agentes educadores em suas atividades educacionais. Essa reflexão tem como objetivo central a análise crítica dos problemas da realidade vivida. Ela proporciona ao supervisor uma orientação substantiva ao docente. Possibilita demonstrar ao docente o caminho para solução de problemas e alcance do sucesso na relação ensino-aprendizagem. O supervisor não é mero reprodutor de esquemas educacionais a serem seguidos e testados pelos docentes. Para Saviani, os agentes educacionais devem exercer uma reflexão sobre a problemática educacional:

Portanto, o que conhecemos normalmente pelo nome de filosofia da educação não o é propriamente, mas identifica-se (de acordo com a terminologia proposta) ora com a "filosofia de vida", ora com a "ideologia". Acreditamos, porém, que a filosofia da educação só será mesmo indispensável à formação do educador; se ela for encarada, tal como estamos propondo, como uma REFLEXÃO (RADICAL, RIGOROSA E DE CONJUNTO) SOBRE OS PROBLEMAS QUE A REALIDADE EDUCACIONAL APRESENTA. (SAVIANI, 1975, p. 12, grifo nosso).

Inicia-se a investigação refletindo a afirmação de Saviani (SAVIANI, 1975, p. 12, grifo nosso) “Acreditamos, porém, que a filosofia da educação só será mesmo indispensável à formação do educador; se ela for encarada, tal como estamos propondo, como uma REFLEXÃO (RADICAL, RIGOROSA E DE CONJUNTO) SOBRE OS 
PROBLEMAS QUE A REALIDADE EDUCACIONAL APRESENTA”, principalmente pela expressão, "se ela for encarada [...] como uma reflexão sobre os problemas que a realidade educacional apresenta [...]. ”. A primeira constatação é a necessidade de se verificar a maneira como é passada a orientação supervisor-professor. Existe reflexão nesse momento? Essa orientação é unilateral? Existe reflexão das propostas discutidas nesse momento? O supervisor reflete sobre as propostas e orientações que serão feitas? A partir das respostas às essas indagações pode-se então verificar se as características da Filosofia e essenciais à educação estão presentes não só nos processos de ensinoaprendizagem, mas também no momento impar que é a orientação ou construção coletiva da reflexão sobre a práxis pedagógica em si e seus produtos.

\section{DESENVOLVIMENTO}

Iniciam-se as reflexões sobre o momento único $\mathrm{e}$ importantíssimo da orientação do coordenador com uma constatação histórica na Filosofia, a importância do diálogo na produção do conhecimento. Essa constatação é presente em diversos filósofos principalmente em Sócrates: 
"Sócrates: - O maior inconveniente da escrita parece-se, caro Fedro, se bem julgo, com a Pintura. As figuras pintadas têm atitudes de seres vivos, mas se alguém as interrogar, manter-se-ão silenciosas, o mesmo acontecendo com os discursos: falem das coisas como se estas estivessem vivas, mas, se alguém os interroga, no intuito de obter um esclarecimento, limitam-se a repetir sempre a mesma coisa". (PLATÃO, 275.7 apud PESSANHA, 1980).

Nesse trecho Sócrates argumenta com Fedro de se manter os pensamentos na escrita, a importância de mantê-los escritos ou não. Ele responde a Fedro que o pensamento na escrita se torna inerte, tal como o diálogo sem esclarecimento ou o monólogo. O diálogo sem interação, sem esclarecimento não produz conhecimentos e como disse Sócrates "limitam-se a repetir sempre a mesma coisa". O diálogo também é citado no artigo "As interfaces da atuação do coordenador pedagógico: contribuições aos docentes" de Andrade e Anjos como ferramenta essencial no trabalho do coordenador pedagógico, a saber:

Porém, para que cada uma dessas interfaces ocorra é necessária a existência de um espaço dialógico e a criação de novos tempos e espaços para que as trocas aconteçam efetivamente. Somente com diálogo é que professores coordenadores pedagógicos e gestores conseguirão se aproximar, assumindo assim, cada qual, a sua parcela de contribuição para o sucesso do trabalho educativo. (ANDRADE; ANJOS, p. 4024). 
O que se percebe atualmente no espaço escolar é pouco ou nenhum momento para desenvolvimentos de diálogos que permitam desde participações corriqueiras da vida escolar à gestão democrática ou o importantíssimo momento da construção coletiva da práxis pedagógica, dos elementos essenciais a serem desenvolvidos em sala de aula. Nesse momento de construção coletiva da práxis pedagógica temse a junção dos profissionais responsáveis por ela o coordenador pedagógico e o professor. Esse momento deveria ser do diálogo, da análise crítica, da construção coletiva. Entretanto se torna diversas vezes um repasse de modelos curriculares prontos, seja pelo coordenador que assim age ou pelo professor que recebe a orientação e não questiona, não analisa, não propõe. O diálogo se torna um monologo.

Outra problemática que interfere no diálogo entre coordenador e professor e também no espaço escolar é resistência a multiplicidade de opiniões e posições contrárias em diversos assuntos. Os membros da comunidade escolar percebem os conflitos de opiniões e posições como algo negativo. Aliás, esse fato é comum na sociedade. As pessoas, em sua maioria, consideram a diversidade como um fator negativo e resistem às adversidades. Estão anestesiadas nos diálogos e na realidade 
vivida, consideram-na estática. Não consideram o dinamismo dos diálogos e da realidade.

Nas escolas pesquisadas, ainda que as interfaces ocorram, constataram-se as dificuldades, a qualidade e a intensidade dos encontros pedagógicos entre estes atores, sendo que muitas vezes os encontros e trocas são realizados de forma improvisada nos corredores da escola. Outro aspecto desvelado é a pouca iniciativa dos professores e coordenadores de reivindicar e propor propostas de formação em serviço, garantido por sua vez esses tempos e espaços de encontros com maior qualidade e intensidade. (ANDRADE; ANJOS, p. 4024).

Dificuldades a parte, a questão central, aqui em discussão, está na ausência de diálogo, a qualidade desse diálogo e a percepção da realidade escolar como estática, não existência de uma dinâmica no ensino-aprendizagem e, por conseguinte nas interações entre professor e coordenador:

Neste sentido, concordamos com Freire (1987) quando afirma que a educação não deve ser apenas uma fonte transmissora de conhecimentos para formar um sujeito intelectualmente competente. Educadores e educandos devem, juntos, construir e reconstruir os conhecimentos, baseados numa visão da totalidade. Isto nos remete a uma educação que leva em conta a palavra do homem. "Ao dizer a sua palavra, pois, o homem assume conscientemente sua essencial condição humana. [...] A educação reproduz, assim, em seu plano próprio, a estrutura dinâmica e o movimento dialético do processo 
histórico de produção do homem. Para o homem, produzir-se é conquistar-se, conquistar sua forma humana" (GASPARIN; SILVA, p. 12).

Essa ausência de percepção da dinâmica escolar, de sua totalidade, interfere por sua vez no processo da dialética reflexiva, do diálogo esclarecido como propunha Sócrates. O diálogo se torna excluso da dinâmica escolar e social. Torna-se um fazer por fazer, uma reprodução de arquétipos a serem aplicados no processo de ensinoaprendizagem. Como afirmava Hegel (NOVELLI, 2005) a realidade é um movimento dialético, um devir continuo, um momento prepara o outro ao mesmo tempo em que um se desfaz para surgimento do outro, assim como a totalidade almejada na dinâmica escolar ou fora dela, surge não somente das concordâncias, mas das diversas fases, inclusive da adversidade, da oposição:

Hegel pensa, sobretudo na vida mais viva, a que não tolera a fixação, o endurecimento, nem a repetição monótona: a vida das relações humanas, a vida social, a vida do espírito e de suas obras, a História. (D`HONDT, 1984).

A ausência do diálogo reflexivo, da percepção da dinâmica no espaço escolar e nas relações didático-pedagógicas entre professores e coordenadores tornam o ensino-aprendizagem uma "repetição 
monótona" o oposto do que pensava Hegel sobre a realidade do espírito (razão) na sociedade, na vida humana. Da mesma forma que para ele a vida deveria ser mais viva, ou seja, é natural das relações humanas a dinâmica da mudança, da oposição. Enquanto que a resistência à dinâmica e ao diálogo nas relações interpessoais na escola permite uma constância de metodologias e sistemas e impede a inovação, a mudança deveria ser uma dialética natural e continua.

Além da problemática da ausência ou qualidade do diálogo, da resistência à dinâmica natural da vida, o professor e coordenador escolar carecem de vontade de mudança, da análise crítica de sua situação vivida, das propostas que lhe são feitas. Estão acostumados com o pré-estabelecido, com as atividades corriqueiras com o domínio velado de sua razão crítica:

Uma vontade que jamais se decide sobre coisa alguma não é uma vontade efetiva, real; de igual modo o homem sem caráter nunca chega a decisão alguma. A razão da indecisão pode residir no fato de que a escolha significa uma limitação, um envolvimento com o finito que nega o infinito. Muito embora tal disposição seja bela, ela é, contudo, morta. (HEGEL, 2000, p. 64).

Entretanto, toda a problemática vivida pelo professor e coordenador escolar não contém a solução em si. A preocupação maior seria sim a maneira como eles resolvem ou não a problemática vivida. 
Eles conseguem perceber a problemática vivida? Percebem-se, conseguem produzir análise sobre ela e elaborar raciocínio critico capaz de conduzi-los a uma vontade, a uma decisão? Conseguem produzir diálogo reflexivo sobre a problemática vivida e sobre as metodologias estabelecidas ou propostas a eles? Percebem que a realidade escolar é dinâmica e exige reflexão sobre essa dinamicidade?

O que afirma Andrade e Anjos no seu artigo "As interfaces da atuação do coordenador pedagógico" é que os envolvidos não conseguem fazer tais análises, nem mesmo o diálogo que possibilitaria tais reflexões:

No entanto, as respostas da maioria levam a constatação de duas situações preocupantes: tanto professores quanto coordenadores pedagógicos precisam de mais aproximação, mais diálogo e cooperação mútua, pois, em alguns casos expostos na pesquisa, um fica esperando que o outro o procure e ao fim, reclamam da falta de iniciativa um do outro. (ANDRADE; ANJOS, 2007).

Além dos problemas acima citados, o coordenador também perde sua autonomia, poder de decisão e diálogo com o professor quando tem que repassar ao mesmo normas pré-estabelecidas sem possibilidade de análise e critica. Ou seja, a possibilidade de reflexão sobre os planejamentos e ideias discutidas entre coordenador e professor são limitadas pela imposição de modelos que engessam as 
possibilidades de discussões. Um depoimento retirado do relatório " $\mathrm{O}$ coordenador pedagógico e a formação de professores: intenções, tensões e contradições.”, pesquisa desenvolvida pela Fundação Carlos Chagas por encomenda da Fundação Victor Civita de junho de 2011:

Ao analisar a influência da legislação na ação do CP, três delas dizem que interfere muito e de forma negativa: "Interfere muito, tira a autonomia de todos, não temos poder de decisão, pois as coisas vêm de cima para baixo" (PLACCO; ALMEIDA; SOUZA, 2011, grifo do autor.).

Sendo o coordenador um articulador, um mediador de conhecimento, de estratégias de organização e produção do ensinoaprendizagem, de possibilidade de reflexão sobre atos e ações desse certame, como proporcionar diálogo e reflexão se é privado de sua autonomia, de seu poder de decisão? Como desenvolver diálogos critico-reflexivos com os professores se existem limitadores dessa prática?

Uma proposta para o desenvolvimento dos diálogos criticoreflexivos seria despertar nos partícipes o interesse e a importância deles para a construção coletiva de conhecimento, de que o pensamento racional deles permitiria uma variedade de possibilidades criativas e construtivas. Do consenso dessa pluralidade se obteria um conhecimento de qualidade e construído pelos partícipes. Esse 
consenso não se dá ao acaso. Ele é obtido da variedade de proposições ocorridas no diálogo.

Aparece, então, a dimensão formativa no trabalho do CP, tanto em relação a sua própria formação quanto à formação dos professores. Essa dimensão, que entendemos como um dos eixos que estruturam e sustentam a função do $\mathrm{CP}$, não aparece quando estabelecem relações entre as características de seu trabalho e as da docência (PLACCO; ALMEIDA; SOUZA, 2011).

Habermas, filósofo contemporâneo, tem em sua filosofia propõe uma "ação comunicativa", ela considera o diálogo e o consenso como ferramentas essenciais ao ser humano e sua vida social. Para este filósofo essas ferramentas são tão importantes que seriam fundamentais na construção da ética que norteia os princípios básicos de convivência social. Elas seriam capazes também de desfazer as relações de poder que inibiriam o diálogo e o consenso e as formas autoritárias de proposições que se efetivariam parcialmente:

Chamo ação comunicativa àquela forma de interação social em que os planos de ação dos diversos atores ficam coordenados pelo intercâmbio de atos comunicativos, fazendo, para isso, uma utilização da linguagem (ou das correspondentes manifestações extra verbais) orientada ao entendimento. À medida que a comunicação serve ao entendimento (e não só ao exercício das influências recíprocas) pode adotar para as interações o papel de um 
mecanismo de coordenação da ação e com isso fazer possível a ação comunicativa. (HABERMAS, 1997; p.418, grifo do autor).

Em sua Teoria da Ação Comunicativa, Habermas apresenta vários argumentos para sustentar a importância do diálogo e da construção coletiva do consenso sobre as várias questões da vida humana e também na educação. A comunicação, o diálogo é fundamental na educação, através dela se prossegue a construção do conhecimento:

Quando os pais querem educar os seus filhos, quando as gerações que vivem hoje querem se apropriar do saber transmitido pelas gerações passadas, quando os indivíduos e os grupos querem cooperar entre si, isto é, viver pacificamente com o mínimo de emprego de força, é obrigados a agir comunicativamente (HABERMAS, 1993; p.105).

Habermas destaca também a importância da participação dos sujeitos envolvidos no diálogo, não é simplesmente no dialogar, mas como possibilitadores e elaboradores de decisões. São responsáveis pelo diálogo e pelas decisões consensuais dele:

Os intérpretes renunciam à superioridade da posição privilegiada do observador, porque eles próprios se vêem envolvidos nas negociações sobre o sentido e a validez dos proferimentos. Ao tomarem parte em ações 
comunicativas, aceitam por princípio o mesmo status daqueles cujos proferimentos querem compreender. Eles não estão mais imunes às tomadas de posição por sim/não dos sujeitos de experiência ou dos leigos, mas empenham-se num processo de crítica recíproca. No quadro de um processo de entendimento mútuo-virtual ou actual- não há nada que permita decidir a priori quem tem de aprender de quem (HABERMAS, 1989; p.43).

Assim, Habermas destaca em sua filosofia da Teoria da Ação Comunicativa as ações fundamentais do diálogo e do consenso para vida humana e para a educação. Sua teoria se aplica principalmente aos sujeitos que constroem as diretrizes da práxis educacional, portanto, também aos coordenadores e professores com função primordial de através da comunicação promover conhecimento de qualidade e fruto da coletividade de raciocínios criativos e reflexivos.

Além da coletividade, dos diálogos reflexivos a limitação provocada pelas legislações educacionais impostas sem reflexão é passível de questionamento quando o próprio coordenador as questiona. Ele identifica a limitação, a questiona e a torna em um objeto de reflexão sua e da coletividade ao qual é responsável. Dessa reflexão imerge a necessidade de mudança:

A questão do "controle" é aqui retomada sob o ponto de vista do profissional, agora não ligado somente ao "exercer o controle sobre", mas também "sendo controlado por". É o que alerta Sabrina, ao se discutir o 
controle como atribuição tanto do supervisor quanto do orientador posto pelas legislações até 1998. (FRANCO, 2006).

Diálogos retirados do artigo "Coordenador Pedagógico: identidade em questão" de Denise Vieira Franco ilustra com clareza a questão da legislação imposta e a postura do supervisor perante essa situação:

Sabrina: Você ia às escolas, você via como as coisas estavam acontecendo, está entendendo? Então praver como é que as coisas estavam acontecendo, se elas estavam realmente trabalhando, se elas estavam presentes, se realmente elas iam... tinha todo esse lado mesmo. E nós também éramos. Então quer dizer, a gente fazia a função e a gente também era controlada nesse sentido, né? [...] Eu como professora vivi isso muito no Estado, era tudo fruto de uma época mesmo. (FRANCO, 2006).

Neste relato de Sabrina está nítida a influência do "controle" do sistema educacional sobre a identidade do coordenador através das ações que lhes são impostas, seja na função de controlar as ações do professor ou através de documentos, diretrizes, que ao invés de serem construídos coletivamente e mediante da realidade de cada escola são impostos como orientações a serem seguidas. Muitos coordenadores, quando ausentes de capacidade reflexiva, aceitam passivamente essas imposições e conduzem seus professores para a mesma posição. 
Ainda buscando relacionar o aspecto legal à construção da identidade, algumas coordenadoras expuseram o seguinte:

Dara: Não, eu acho que a identidade teria que partir debaixo, não vir uma coisa de cima, igual coloca assim as atribuições, é. ouvir mais as pessoas que estão trabalhando nisso pra se construir alguma coisa. [...] Tem que escutar a classe, exatamente. Pra ela colocar fielmente o que se propõe (FRANCO, 2006).

Quando Dara se posiciona com relação à identidade não vir de cima ela está praticando um pensamento crítico-reflexivo, como proposto nas diretrizes filosóficas. Todo conhecimento exercido através dessas diretrizes, além do rigor, da autenticidade deve seguir imprescindivelmente a autonomia. Na fala de Dara essa autonomia se estende à coletividade quando ela afirma que as pessoas constroem alguma coisa. Essa construção pressupõe a autonomia do pensamento, o refletir, o fazer por si mesmo sem imposições externas.

Mariana: Mexe com a nossa identidade? Mexe, a partir do momento que a legislação quando chega na escola de forma imposta. São pacotes que são jogados na escola, que muitas vezes ignoram o contexto social, as especificidades de cada escola e aí o quê? Mexe com a nossa identidade. Por quê? Esse pacote ele vem num momento que interessa a quem, a quem? A alguém lá de cima do sistema, algum burocrata da educação que quer que, naquele momento as coisas aconteçam daquela forma. (FRANCO, 2006). 
Nessa fala da coordenadora Mariana está presente a indignação sobre a legislação imposta, e as suas influências negativas que tem destaque na interferência da identidade do coordenador, não considerar a realidade da escola e interferir na relação entre coordenador e professor. Tanto coordenadores quanto professores necessitam de imediato repensar a sua práxis pedagógica, questionar as dimensões do seu conhecimento, sua maneira de pensar e olhar a totalidade envolta. Os depoimentos acima descritos retirados da dissertação de Franco nos exemplificam um momento ímpar de reflexão sobre algo que lhes é imposto.

A reflexão, o diálogo não se deve somente quanto à legislação imposta como acima citado, mais nos diversos aspectos da vivência desses participes do sistema educacional (coordenadores e professores). Eles precisam vivenciar uma prática reflexiva. O coordenador, como orientador, se torna um agente transformador a partir do momento que transforma a si mesmo e provoca essa reflexão / mudança nos seus orientandos. Essa mudança é possível através da reflexão de suas próprias ações. Essa reflexão é possível através das diversas áreas do conhecimento, principalmente pela Filosofia como citada nesse 
trabalho em diversas situações, nos mais ilustres filósofos e em destaque no segundo parágrafo da introdução do mesmo.

Tal qual a legislação imposta existem literaturas propostas aos coordenadores que não permitem sua reflexão, apenas apreensão de um conhecimento sem questionamento. Essa problemática foi descrita no artigo "O que revelam as pesquisas sobre a atuação do coordenador pedagógico” de Miziara, Ribeiro e Bezerra:

Nesse sentido, a literatura apropriada, muitas vezes, não é de caráter científico, [...] mas com abordagem pragmática, do tipo manual, que se encontra facilmente disponível na internet ou revistas. Tal situação contribui para que a orientação do trabalho pedagógico na educação resvale no pragmatismo e os profissionais acabem reduzindo seu papel à execução de 'projetos' elaborados por outrem. (ALVES, 2007 apud MIZIARA; RIBEIRO; BEZERRA, 2014).

Um exemplo de manual imposto pelo sistema educacional, principalmente o sistema estadual, são os Conteúdo Básico Comum (CBC). Documento extenso com propostas curriculares a serem seguidas por professores e coordenadores no momento da elaboração dos planejamentos bimestrais/anuais para as diversas etapas/ciclos e disciplinas. Se o coordenador não possuir uma visão critico-reflexiva sobre esse documento, por exemplo, tornará suas diretrizes uma obrigação a ser seguida sem questionamento pelos professores na sua 
extensão sem refletir sobre os conteúdos que poderiam ser aplicados à realidade dos alunos e da comunidade ao qual ele advém. Tal como o $\mathrm{CBC}$, vários manuais ou literaturas, que não possuem uma orientação reflexiva sobre seus conteúdos conduzem seus leitores a uma passividade de reflexão quanto ao que está lendo ou que pretende elaborar.

A falência das orientações "enlatadas" aos coordenadores reforça o discurso de que a teoria não soluciona os problemas educacionais, sendo, portanto, desnecessária. Em outras palavras, o coordenador pedagógico tende a considerar que sua formação continuada pode prescindir de um referencial teórico sólido. Nessa perspectiva, a prática é vista com maior "prestígio". As contribuições de Alves (2007) validam essa tese ao elucidarem que a aprendizagem da função ocorre com base na experiência e com os desafios cotidianos. A pesquisa revela, com nitidez, o perigoso hiato entre a teoria e a prática, "[...] indicando um distanciamento entre os conteúdos aprendidos na formação acadêmica e os saberes requisitados no trabalho cotidiano" (ALVES, 2007, p. 228-229 apud MIZIARA; RIBEIRO; BEZERRA, 2014, grifo do autor).

Logo, pode-se destacar a singularidade da Filosofia em detrimentos de outras literaturas. Ela exige um rigor científico. Intrínseco a este, outras características fundamentais: a problematização, a reflexão, a dinamicidade, autenticidade e principalmente a necessidade de autonomia do ser que pensa. 
"Saviani (2008) sublinha a importância da reflexão filosófica, pois esta possibilita ao coordenador pedagógico superar sua compreensão sobre a prática pedagógica concebida de forma simples, fragmentada, desarticulada, incoerente, orientada pelo senso comum. Diante disso, fica claro que a reflexão filosófica é fundamental para se garantir um direcionamento emancipador e crítico em relação às ações dos coordenadores pedagógicos. Para tanto, faz-se necessário retomar a prática, avaliando suas possibilidades com as reais necessidades dos professores e dos alunos." (MIZIARA; RIBEIRO; BEZERRA, 2014).

Nessa expressão "direcionamento emancipador", de Saviani está contida uma das características imprescindíveis do pensamento filosófico, a autonomia do pensamento, o momento do ser que pensa e questionam seus pensamentos, suas ações. No caso do coordenador pedagógico, momento em que ele reflete e que conduz o outro à reflexão sobre suas ações e pensamentos. Essa reflexão de atos, de atitudes pode ser proporcionada pela Filosofia. O que ela pretende? Um pensamento crítico-reflexivo, uma análise de suas ações, de sua realidade. Filosofia não é só teoria. Ela é uma teoria que pretende o questionamento em si. Depois dele, a reflexão sobre o que foi questionado. Filosofia é o pensamento em si, a maneira como ele é construído ou direcionado. O coordenador que pratica as características 
propostas pela Filosofia na construção do pensamentos conduz seus professores à uma reflexão contínua de ações e pensamentos.

\section{CONSIDERAÇÕES FINAIS}

No decorrer deste trabalho nos deparamos com várias situações nas quais a orientação do coordenador ao professor é passível de análises críticas e suscetíveis de mudança. O coordenador é constantemente influenciado pelas normas pré-estabelecidas, pelo engessamento de ideias, pela leitura acrítica. Mas então, qual é o caminho a se percorrer para proporcionar a mudança nessa maneira de orientar o professor, de exercer uma coordenação pedagógica critica coletiva e reflexiva? O que o coordenador deve usar como diretriz nesse caminho?

A proposta desse trabalho a estas indagações é a Filosofia. Não um a Filosofia pragmática, conteudista e de uso disciplinar. Mas sim, as características impares dela que estão presentes nos mais variados filósofos e suas obras em forma de teoria. Teoria como diretriz de reflexão e não conteúdo repassado como história a ser lembrada. Aqui se fala de características e diretrizes de construção pensamento. A 
saber, o diálogo, a autonomia, a elaboração e a reflexão crítica do pensamento, que se faz continuamente.

Saviani em suas obras já havia notado essas características da Filosofia que se apresentam fundamentais ao educador, mas uma em especial, a reflexão, seria essencial aos agentes educadores em suas atividades educacionais. Essa reflexão tem como objetivo central a análise crítica dos problemas da realidade vivida. Ela proporcionaria ao supervisor a capacidade de uma orientação substantiva ao docente. Possibilitar-nos-ia demonstrar ao docente o caminho critico-reflexivo de solução de problemas e alcance do sucesso na relação ensinoaprendizagem. O supervisor não seria mero reprodutor de esquemas educacionais a serem seguidos e testados pelos docentes. Para Saviani, os agentes educacionais deveriam exercer uma reflexão sobre a problemática educacional.

A Filosofia é importante por suas características fundamentais: criticidade, autonomia, reflexão, não somente para o aluno em formação educacional, mas também para o educador, supervisor e demais agentes da relação ensino-aprendizagem. A percepção com abordagem filosófica permitiria uma análise objetiva e uma solução serena e prática da problemática vivida. Essa abordagem filosófica proporcionaria um novo olhar sobre as relações entre supervisor e 
professor e, por conseguinte às demais vivências desses agentes educacionais.

Filosofia é o próprio pensamento, sua construção. O que é Filosofia? É o próprio pensar já dito por Sócrates, Kant, Hegel e vários outros nomeados filósofos. Mas, é qualquer pensar? Não. O que foi aqui exposto em diversas partes desse trabalho é principalmente a características desse pensamento emancipador. Pensamento, que considera diretrizes fundamentais a criticidade, o questionamento a autenticidade e fundamentação racional para sua prevalência. Um pensamento não basta por si mesmo, ele tem que ser construído e aceito coletivamente não sendo de outra maneira racional. Na relação coordenador - professor esse pensamento solidifica as pretensões de uma qualidade educacional em todas as suas fases.

Enfim, a Filosofia, através de suas teorias filosóficas, seus textos proporcionaria a reflexão tão aclamada nesse trabalho. Uma reflexão que vai além da literatura habitualmente acessada pelo supervisor, com ênfase no pensamento problematizador, critico, reflexivo. $\mathrm{O}$ pensamento autônomo, autêntico, dinâmico, totalizante. Esse pensamento proporcionado pela Filosofia seria uma excelente diretriz de orientação das ações do supervisor e suas relações com o professor. 


\section{REFERÊNCIAS}

ANDRADE, M. R. S.; ANJOS, R. D. As interfaces da atuação do coordenador pedagógico: contribuições aos docentes. Disponível em $<\mathrm{http} / / / \mathrm{www}$.pucpr.br/eventos/educere/educere2007/anaisEvento/arqui vos/CI-488-04.pdf>, acesso em 19 out. 2015.

BECKER, J. Filosofia na pedagogia e ação escolar. Disponível em http://coral.ufsm.br/gpforma/2senafe/PDF/006e3.pdf. Acesso em: 21 jan. 2015.

DA SILVA, Márcia Cristina Amaral; GASPARIN, João Luiz. A teoria da ação comunicativa de Jürgen Habermas e suas influências sobre a educação escolar. Disponível em <http://www.histedbr.fe.unicamp.br/acer_histedbr/seminario/seminari o7/TRABALHOS/M/Marcia\%20CA\%20Silva\%20e\%20\%20Joao\%20 L\%20Gasparin1.pdf>. Acesso em: 29 out. 2015.

D’HONDT, Jacques. Hegel. Lisboa: Edições 70, 1984.

FRANCO, Denise Vieira. Coordenador Pedagógico: Identidade em questão. 2006. Disponível em <http://www.ufjf.br/ppge/files/2009/07/denise.pdf >. Acesso em: 15 jan. 2016.

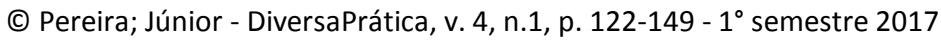


GALLO, ASPIS. Renata Lima, Silvio Gallo. Ensinar Filosofia. São Paulo: Atta Mídia e Educação, 2009.

HABERMAS, Jürgen. Consciência moral e agir comunicativo. São Paulo: Brasiliense, 1989.

Brasileiro, 1993.

. Passado como futuro. Rio de Janeiro: Tempo Teoria de la acción comunicativa: complementos y estúdios prévios. Madrid: Cátedra, 1997.

KOHAN, Walter Omar. Filosofia para crianças. Rio de Janeiro: Lamparina, 2008.

LUCKESI, Cipriano Carlos. Filosofia da Educação. São Paulo: Cortez, 1995.

MIZIARA, L.A.S.; RIBEIRO, R.; BEZERRA, G.F. O que revelam as pesquisas sobre a atuação do coordenador pedagógico. Revista Brasileira de Estudos Pedagógicos, v. 95 n. 241. Brasília, set./dez. 2014. Disponível em: <http://dx.doi.org/10.1590/S21766681/302712683>. Acesso em jan. 2016. 
NOVELLI, Pedro Geraldo Aparecido. O Ensino da Filosofia segundo Hegel: Contribuições para a atualidade. Trans/Form/Ação, São Paulo, n. 28 v. 2: p. 129-148, 2005. Disponível em <http://www.scielo.br/pdf/trans/v28n2/29419.pdf >. Acesso em 31 out. 2015.

PESSANHA, José Américo Motta (org.). Sócrates. São Paulo: Abril Cultural, 1980

PLACCO, V. M. N. S.; ALMEIDA, L. R.; SOUZA, V. L. T. O coordenador pedagógico e a formação de professores: intenções, tensões e contradições. São Paulo: FVC, 2011. Disponível em: $<$ http://www.fvc.org.br/estudos-e-pesquisas/avulsas/coordenadorpedagogico-cp-formacao-professores.shtml>. Acesso em 31 out. 2015.

SAVIANI, Dermeval. A filosofia na formação do educador.

Disponível em: <http://www.scribd.com/doc/7298667/DemervalSaviani-Do-Senso-Comum-Cons-Ciencia-Filosofica>. Acesso em: 12 ago. 2014. 